\title{
ACESSO AO TRATAMENTO ONCOLÓGICO NO SUS: A RESPONSABILIDADE CIVIL DO ESTADO PELA PERDA DA CHANCE DE CURA OU DE SOBREVIDA DAS PACIENTES COM CÂNCER DE MAMA
}

\begin{abstract}
ACCESS TO ONCOLOGICAL TREATMENT IN SUS: THE CIVIL LIABILITY OF THE STATE FOR THE LOSS OF CURE OR SURVIVAL OF PATIENTS WITH BREAST CANCER
\end{abstract}

\author{
Brunize Altamiranda Finger \\ Têmis Limberger
}

\section{RESUMO}

Em 2012, foi criada a Lei 12.732, que fixa o prazo de 60 dias para início do tratamento do câncer na rede pública de saúde. Entretanto, relatórios demonstram índices insatisfatórios de cumprimento dessa regra jurídica. Por essa razão, o estudo objetiva verificar se o Estado pode ser responsabilizado civilmente, e em que condições, pela perda da chance de cura ou de sobrevida das pacientes com câncer de mama que não receberam tratamento pelo SUS no prazo legal. Para tanto, analisaram-se os motivos para fixação do período de 60 dias, pesquisaram-se documentos acerca da efetividade da lei e se examinou a posição da doutrina sobre responsabilidade estatal por omissão. Concluiu-se que o Estado pode ser responsabilizado, desde que três critérios sejam observados: Universalidade do acesso ao tratamento contra o câncer de mama em até 60 dias, Acessibilidade ao tratamento médico frente às barreiras geográficas e Tratamento contra o câncer de mama materialmente possível.

Palavras-chave: Responsabilidade civil do Estado. Dano pela perda da chance. Câncer de mama. 


\section{ABSTRACT}

In 2012, the Law 12.732 was created, which sets the deadline of 60 days for the start of cancer treatment in the public health network. However, reports show unsatisfactory rates of compliance with this legal rule. For this reason, the study aims to verify whether the State can be held civilly responsible, and under what conditions, for the loss of the chance of cure or survival of patients with breast cancer who have not received treatment by the SUS within the legal term. In order to do so, the reasons for setting the 60-day period were analyzed, documents were examined on the effectiveness of the law, and the position of the doctrine on state responsibility for omission was examined. It was concluded that the State can be held responsible, provided that three criteria are observed: Universality of access to treatment against breast cancer in up to 60 days, Accessibility to medical treatment against geographical barriers and Treatment against breast cancer materially possible.

Keywords: Civil liability of the State. Damage to loss of chance. Breast cancer.

\section{INTRODUÇÃO}

Para situar o tema da perda da chance de cura ou de sobrevida dos usuários do Sistema Único de Saúde (SUS), propõe-se o seguinte caso julgado pelo Tribunal de Justiça de Minas Gerais: uma criança sentia fortes dores em seu olho esquerdo. 0 médico da rede pública de saúde diagnosticou que ela tinha infecção ocular. Por haver risco de cegueira de caráter irreversível - se o tratamento não fosse aplicado em tempo oportuno e de forma adequada -, o clínico solicitou encaminhamento urgente ao especialista. A consulta com o oftalmologista, porém, aconteceu depois de quatro meses do pedido de encaminhamento (urgente). Nesse atendimento, constatou-se que a cegueira se tornara definitiva no olho esquerdo da paciente (MINAS GERAIS, Tribunal de Justiça, 2011).

A perda da visão do olho esquerdo da doente é um prejuízo passível de indenização, tendo em vista que a aplicação do tratamento médico poderia curar ou melhorar o estado de saúde dela? Não é possível afirmar com certeza que ela seria curada, todavia, é certo que o atraso no atendimento por especialista diminuiu as chances de curar ou de 
amenizar a inflamação ocular. Essa situação ilustra uma das dificuldades enfrentadas pelos usuários do SUS: a demora em iniciar a aplicação terapêutica.

Segundo pesquisas realizadas pelo Datafolha, a saúde pública é apontada pelos entrevistados, desde 2008, como um dos principais problemas do país ${ }^{1}$. Em 2015, foi apurado que, a cada dez brasileiros, seis classificaram a saúde pública como péssima, sendo o tempo de espera a maior adversidade enfrentada pelos usuários (FOLHA DE SÃO PAULO, 2015).

Esses dados demonstram a necessidade de se discutir o tema em torno da demora na prestação de serviços pelo SUS, pois o diagnóstico e o tratamento realizados no tempo adequado são determinantes para um desfecho favorável (cura, prolongamento da vida ou melhora na qualidade de vida) na maioria das doenças - ou em todas. Essa questão é importante, sobretudo, para pacientes portadores de alguns tipos de câncer, que veem no célere atendimento uma forma de aumentar suas possibilidades de obter um bom resultado. Atrasos podem levar à diminuição das chances de cura, à necessidade de procedimentos mais invasivos ou ao surgimento de metástases - piorando o prognóstico.

Estudos apontam que existem mais de 200 tipos de câncer. Neste artigo, analisa-se a perda da chance nos casos de câncer de mama. A incidência desse tumor e a mortalidade causada por ele é maior entre as mulheres. ${ }^{2}$ Em 2012 foram estimados 500 mil óbitos no mundo por esse tipo de câncer. Isso significa que, de todos os óbitos no mundo em razão de neoplasias malignas, 15\% foram causados pelo câncer de mama (INCA, 2015, p. 33). Para 2016, o INCA estimou 57.960 mil novos casos de câncer de mama, sendo a parte Sul do país a que apresentou a maior taxa de frequência: 74 casos a cada 100 mil mulheres (2015, p. 32). Por essa razão, o estudo empírico da presente pesquisa foi realizado nessa região, especificamente no Rio Grande do Sul.

Apesar da alta incidência da doença, bem como ser o seu índice de mortalidade alarmante, se diagnosticada e tratada no tempo adequado, as chances de cura são promissoras. A probabilidade de cura ou maior sobrevida depende do estadiamento ${ }^{3}$ do tumor; se ele ainda se encontrar na região da mama, por exemplo, a chance de cura chega a 95\%. Quanto 
mais distante estiver o tumor desse loco (mama), menores são as chances de cura. Percebe-se, portanto, que a detecção precoce e o tratamento tempestivo são elementos significativos para um bom prognóstico. Entre esses dois elementos, o presente estudo foca no tratamento tempestivo, sobretudo em razão da Lei 12.732/2012, que fixou a garantia de o paciente com câncer iniciar seu primeiro tratamento médico pelo SUS no prazo máximo de 60 dias após o diagnóstico.

Pelos motivos expostos, objetiva-se responder à seguinte questão: é possível que o Estado brasileiro seja responsabilizado civilmente pela perda da chance de cura ou de sobrevida das pacientes com câncer de mama que não conseguiram acessar o primeiro tratamento médico em até 60 dias? Em caso positivo, em que condições?

Os métodos utilizados para responder ao problema de pesquisa foram o fenomenológico-hermenêutico, para investigar e estabelecer critérios de responsabilização civil do Estado quando este não efetiva de modo satisfatório os direitos sociais, especificamente o direito à saúde. E o método indutivo, pois foi realizada coleta de dados referentes ao tempo para iniciar tratamento, contidos na plataforma Integrador RHC, administrada pelo INCA. A finalidade foi obter generalizações sobre o tratamento fornecido pelo SUS para as pacientes com câncer de mama, a partir de informações da rede pública de saúde no Rio Grande do Sul.

\section{LEI 12.732/2012: CÂNCER VERSUS TEMPO}

A Lei 12.732/2012 é uma valiosa medida para aumentar as chances de cura ou de sobrevida para os que têm câncer. Uma das principais medidas dessa regra jurídica é o direito de iniciar o seu tratamento médico no prazo máximo de 60 dias no SUS, contado a partir do dia em que foi firmado o diagnóstico em laudo patológico - motivo que a tornou popularmente conhecido como Lei dos 60 dias. Esse período de espera, no entanto, poderá ser menor na hipótese de o paciente apresentar essa necessidade (artigo $2^{\circ}$ ).

A lei também versa sobre a qualidade do serviço público prestado: o $1^{\text {o }}$ do art. 1ํ determina que a padronização de terapias do câncer, 
cirúrgicas e clínicas deverá ser revista, republicada e atualizada sempre que necessário. Os pacientes com dor causada pela patologia terão tratamento privilegiado e acesso gratuito a analgésicos opiáceos ou correlatos (artigo, $2^{\circ}$, $§ 2^{\circ}$ ). Em caso de não cumprimento do previsto na referida lei, os gestores responsáveis (direta ou indiretamente) pelo serviço serão penalizados administrativamente - conforme prevê o artigo 3o (BRASIL, Lei 12.732, 2012).

\section{Por que 60 dias?}

Ao se examinar as notas taquigráficas da sessão de deliberação do PL 3.887-B/1997, é possível entender que a fixação do prazo de 60 dias foi resultado de uma interlocução entre variados responsáveis pela promoção do direito à saúde. Isso porque a deputada Flávia Morais afirmou, em seu discurso, que as medidas trazidas no projeto foram fruto de um consenso entre as lideranças do Governo e os partidos políticos envolvidos (BRASIL, 2012, p. 20483).

É provável que o período máximo de espera fixado reflita um equilíbrio entre o tempo que o paciente com câncer pode esperar sem ser prejudicado e a capacidade de recursos financeiros e técnicos (profissionais, equipamentos, espaço, etc.) que o Estado brasileiro detém atualmente para prestar esse serviço. Segundo a deputada Carmen Zanotto, o citado PL assegura ao paciente com câncer o primeiro tratamento em até 60 dias “(...) por um grande acordo que foi feito com o Governo, junto com todas as Lideranças dos partidos, porque no projeto original nós estávamos, nas primeiras discussões, nos 30 dias, porque é importante aprazar" (BRASIL, 2012, p. 20483).

0 período de 30 dias diz respeito ao tempo médio de espera para iniciar o tratamento oncológico em alguns países, como no Canadá. Nesse país, a meta é iniciar, ao menos para 75\% dos pacientes, a radioterapia em até 28 dias a partir do momento em que o paciente estiver apto para iniciar o tratamento médico. No ano de 2009, conforme dados do Canadian Institute for Health Information, 88\% dos portadores de neoplasia maligna 
iniciaram essa modalidade terapêutica no prazo, superando a meta fixada (CANADIAN INSTITUTE FOR HEALTH INFORMATION, 2010, p. 5).

No Brasil, entretanto, tais prazos não são viáveis atualmente. Salvo alguns poucos hospitais públicos de excelência, a rede pública de saúde não tem capacidade para oferecer tratamento contra o câncer em períodos semelhantes. Nesse sentido, o deputado Marcus Pestana apontou o subfinanciamento do SUS como um dos motivos para essa incapacidade (2012, p. 20485). Significa dizer que a mera criação de lei não é capaz de modificar a realidade. É preciso que haja a aplicação de recursos para que o comando da regra jurídica produza efeitos, alcançando o maior número de pessoas que necessitam daquele serviço público.

\section{(IN)EFETIVIDADE DA LEI DOS 60 DIAS: PESQUISA DOCUMENTAL E AVALIAÇÃO DO INTERVALO DE TEMPO ENTRE DIAGNÓSTICO E ACESSO AO PRIMEIRO TRATAMENTO MÉDICO CONTRA O CÂNCER DE MAMA}

É por meio das novas tecnologias que a maioria das informações é divulgada, sobretudo pela Internet, a qual torna o acesso mais dinâmico e a baixo custo para o cidadão. Esse novo cenário digital vem permitindo o desenvolvimento de uma nova forma de exercer a cidadania, pois a disponibilização de informações públicas em rede viabiliza melhores condições para o cidadão informar-se acerca da gestão pública (LIMBERGER, 2015, p. 2654). Nesse sentido, a Lei 12.527/2011 (Lei de Acesso à Informação Pública) ratifica essa nova tendência ao estabelecer que os órgãos e as entidades públicas divulguem as informações de interesse coletivo - salvo as qualificadas como confidenciais - por meio de todas as formas disponíveis e obrigatoriamente em sítios da Internet.

No que diz respeito às informações sobre saúde, particularmente na área oncológica, há, no Brasil, os Registros de Câncer de Base Populacional (RCBP), que dizem respeito ao impacto do câncer na população por meio de uma avaliação de incidência e de mortalidade, e os Registros Hospitalares de Câncer (RHC), que são sistemas implantados em hospitais e unidades hospitalares que prestam assistência de Alta Complexidade 
em Oncologia. O RHC possibilita identificar o perfil dos pacientes com esse diagnóstico e os recursos e tratamentos utilizados em cada hospital. Essas informações são divulgadas no Integrador RHC - um sistema Web desenvolvido pelo INCA.

A finalidade dos Registros Hospitalares de Câncer é coletar dados sobre diagnóstico, tratamento e evolução dos pacientes com câncer atendidos em hospitais gerais ou especializados na área - os quais podem ser públicos, privados, filantrópicos ou universitários -, bem como colaborar com a melhoria da gestão hospitalar e dar apoio ao desenvolvimento de pesquisas clínicas. A principal fonte de informação são os prontuários médicos dos pacientes. Para que a equipe de saúde consiga acompanhar os casos e para que seja possível compilar as informações sobre os tratamentos aplicados em dados estatísticos, é preciso que as informações sejam padronizadas, utilizando classificações e codificações nacionais e internacionais (INCA, 2010, p. 17).

Em 1988, o Ministério da Saúde tornou os Registros Hospitalares de Câncer uma obrigação para os centros de atendimento oncológico. Esse dever foi ratificado em 2005, quando se instituiu a Política Nacional de Atenção Oncológica (Portaria 2.429/GM/MS). No artigo 5ํ desse texto legal, ficou previsto que o credenciamento e funcionamento de hospital como prestador de serviço de alta complexidade em oncologia dependia, dentro outros requisitos, da existência de um Registro Hospitalar de Câncer. Após credenciamento, tais hospitais passam a ter a obrigação de enviar periodicamente os dados do RHC ao INCA (uma vez ao ano, no mês de setembro).

\section{Método}

Nesta etapa do trabalho, utilizou-se como procedimento técnico o documental, valendo-se de tabelas estatísticas e de relatórios do Integrador RHC. Nele, foi possível encontrar e tabular informações referentes ao intervalo de tempo entre o resultado da biópsia (diagnóstico) e o início do tratamento médico, permitindo, portanto, avaliar em que medida a Lei $12.732 / 2012$ foi cumprida no período proposto ${ }^{4}$, no estado 
do Rio Grande do Sul. Como referência para avaliar os resultados da lei em estudo, retroagiu-se o mesmo período de vigência do texto legal quando realizada a pesquisa (agosto de 2016) - como será demonstrado a seguir.

\section{Resultados}

Os dados do Integrador RHC para o ano de 2010, 2011 e 2012 demonstraram que $77,7 \%, 72 \%$ e 78,1\%, respectivamente, das pacientes com câncer de mama "sem diagnóstico e sem tratamento" 5 conseguiram iniciar seus tratamentos nos primeiros 60 dias a partir do diagnóstico. Já os índices de acesso das usuárias "com diagnóstico e sem tratamento"6, no mesmo período, são de 51,7\%, 47\% e 37,5\%.

Após a entrada em vigência da Lei 12.732/2012, em maio de 2013, verificou-se que, nos anos de 2013, 2014 e 2015, 74,4\%, 85,8\% e 69\% respectivamente - das portadoras de câncer de mama "sem diagnóstico e sem tratamento" tiveram a instituição do tratamento médico no prazo. No que tange às pacientes "com diagnóstico e sem tratamento", observouse que $42,2 \%, 36,7 \%$ e $31,2 \%$, no mesmo período citado, iniciaram o tratamento médico dentro dos 60 dias.

Tabela 1 - Síntese da frequência do tempo transcorrido entre diagnóstico de câncer de mama e instituição do primeiro tratamento no período de 2010 a 2015

\begin{tabular}{c|c|c|c}
\hline Ano & $\begin{array}{c}\text { Número de casos } \\
\text { de câncer de mama } \\
\text { enviados pelas unidades } \\
\text { hospitalares do RS } \\
\text { ao INCA contendo } \\
\text { informações sobre } \\
\text { a data do início do } \\
\text { tratamento* }\end{array}$ & $\begin{array}{c}\text { Acesso ao 10 } \\
\text { tratamento } \\
\text { em até 60 } \\
\text { dias - Sem } \\
\text { diagnóstico e } \\
\text { sem tratamento } \\
(\%)\end{array}$ & $\begin{array}{c}\text { Acesso ao 10 } \\
\text { tratamento } \\
\text { em até 60 } \\
\text { dias - Com } \\
\text { diagnóstico e } \\
\text { sem tratamento } \\
(\%)\end{array}$ \\
\hline 2010 & 1.406 & 77,7 & 51,7 \\
\hline 2011 & 1.504 & 72 & 47 \\
\hline 2012 & 1.310 & 78,1 & 37,5 \\
\hline 2013 & 1.223 & 74,4 & 42,2 \\
\hline
\end{tabular}




\begin{tabular}{c|c|c|c}
\hline 2014 & 842 & 85,8 & 36,7 \\
\hline 2015 & 280 & 69 & 31,2 \\
\hline
\end{tabular}

Fonte: elaborada pela própria autora com base nos dados do Integrador RHC.

* Número de dados disponíveis no Integrador RHC em 02 ago. 2016.

\section{Discussão}

As taxas de incidência dos casos de câncer de mama vêm aumentando. No Rio Grande do Sul, em 2010, o risco estimado de casos dessa neoplasia maligna foi de 81,57/100 mil mulheres; para o biênio 2014/2015, o INCA aferiu que ocorreriam 87,72 ocorrências a cada 100 mil gaúchas (2014, p. 92). Conforme Alessandra Kaercher et al., o aumento da incidência desse tipo de câncer vem acompanhado pela elevação da taxa de óbitos. Um dos principais motivos para isso é o atraso no diagnóstico e no início da aplicação terapêutica adequada (2014, p. 104). Segundo Souza et al:

A demora pode prejudicar o prognóstico das pacientes, reduzindo as chances de cura por crescimento e evolução do tumor. Existe uma associação entre o atraso no diagnóstico e tratamento com pior sobrevida livre da doença, ocorrência de metástase linfonoidal, tamanho do tumor e estadiamento tardio, já a detecção precoce relaciona-se com maiores taxas de cura (SOUZA et al, 2015, p. 3806).

A Lei 12.732/2012, portanto, representa um avanço importante na diminuição de mortes, na medida em que o começo do tratamento oncológico em tempo oportuno evita a redução das chances de cura ou de sobrevida da doente. Por outro lado, o tempo de espera para usufruir dos serviços do SUS é o principal problema apontado pelos seus usuários. Tal dificuldade foi constatada nesta pesquisa: durante o período avaliado (2010 a 2015), observou-se que a média de pacientes com câncer de mama que iniciaram o tratamento no prazo, no segmento "sem diagnóstico e sem tratamento", foi de 76,1\%. Por outro lado, o segmento "com diagnóstico e sem tratamento" apresentou um índice bem menor: $41 \%$. 
Ademais, percebeu-se que, desde a criação da lei, não houve aumento de atendimentos dentro dos 60 dias - exceto no ano de 2014, no segmento "sem diagnóstico e sem tratamento", em que se observou uma maior taxa de atendimento dentro do prazo de 60 dias: 85,8\%, (dos 212 casos registrados no Integrador RHC). Na linha "com diagnóstico e sem tratamento", pós-lei, a maior cifra foi constatada no ano de 2013: 42\%. Em pesquisa realizada por Souza et al, os autores identificaram que das mulheres atendidas em até 60 dias, $6 \%$ tiveram recidiva e 16\%, metástase. Do grupo que não iniciou o tratamento no prazo, 12\% apresentaram recidiva e $21 \%$ evoluíram para metástase (2015, p. 3809).

A próxima constatação diz respeito ao tratamento desigual relacionado ao modo como a paciente chega ao centro de referência: pacientes encaminhadas conforme as regra do sistema - isto é, chegam ao hospital referência com diagnóstico confirmado ou com forte indícios da presença de tumor - aguardam mais tempo para receber a primeira aplicação terapêutica que as doentes encaminhadas diretamente ao centro de referência ${ }^{7}$ - o que também foi verificado por Souza et al. Segundo os autores, as pacientes que chegaram ao hospital sem diagnóstico e sem tratamento levaram menos tempo para receber a primeira aplicação terapêutica, quando comparadas às que chegaram com diagnóstico. Os autores concluíram que receber o diagnóstico no centro de referência favoreceu o acesso ao tratamento médico (2015, p. 3808).

Outra questão não passa despercebida: o montante de casos registrados no sistema é muito menor que a previsão de incidência de casos de câncer de mama prevista pelo INCA para cada um dos anos analisados (no estado do RS). Em 2010, por exemplo, esperava-se 4.750 novos casos; o relatório do tempo, entretanto, apresenta apenas 1.406. É possível que isso seja causado pelo registro incompleto dos dados da paciente e do tratamento, ou pelo não registro das informações de forma adequada - dentre outros motivos. No Anexo A, pode-se observar no relatório "Número de casos por Ano de 1a consulta segundo Unidade Hospitalar", gerado no sistema do Integrador RHC, que há hospitais no estado gaúcho que não tornaram o registro de dados dos pacientes oncológico um hábito. É provável que isso seja causado pela falta de corpo técnico para executar a tarefa, pela ausência de capacitação do pessoal 
responsável por esse processo e/ou pela falta de estrutura adequada para isso (instalação do sistema, arquivos organizados e equipamentos técnicos), por exemplo.

Conforme Barros, Uemura e Macedo, a deficiência ou a falta de dados sobre o câncer de mama é observada com mais frequência em países em desenvolvimento do que nos desenvolvidos (2012, p. 35). Souza et al também aponta a mesma constatação: "Registrar os dados, em países em desenvolvimento, é uma tarefa complexa, considerando a falta de recursos materiais e humanos. 0 risco de distorções é fato, e a completude, muitas vezes, é baixa" (2015, p. 3810). Nessa perspectiva, Felipe Ojeda pontua que a falta de informação, ou a informação incompleta, relacionada ao cumprimento de qualquer direito humano, sobretudo do direito à saúde, pode gerar consequências perigosas; uma delas é a falta de garantia do correto funcionamento dos serviços de saúde (2013, p. 191-192). Ademais, um RHC completo e atualizado fornece subsídios para aprimorar a gestão do hospital que envia aos dados, pois é possível visualizar de forma sistemática e organizada os exames e os tratamentos utilizados, assim como o tempo que cada serviço levou para iniciar e finalizar.

Conclui-se, por meio dos dados coletados, que a entrada em vigor da Lei dos 60 dias não trouxe, até o momento, resultados significativos. A situação é mais grave quando se identifica que há tratamento desigual, que está relacionado à maneira como a paciente é encaminhada ao centro de referência.

\section{DANO PELA PERDA DA CHANCE DE CURA OU DE SOBREVIDA DAS PACIENTES COM CÂNCER DE MAMA: PARÂMETROS PARA POSSÍVEL RESPONSABILIZAÇÃO DO ESTADO}

$\mathrm{Na} \mathrm{CF} / 88$, a responsabilidade civil do Estado está fundamentada no $\S 6$ 60 do artigo 37. 0 texto dispõe: As pessoas jurídicas de direito público e as de direito privado prestadoras de serviços públicos responderão pelos danos que seus agentes, nessa qualidade, causarem a terceiros, assegurado 
o direito de regresso contra o responsável nos casos de dolo ou culpa. 0 fundamento desse dispositivo legal é a teoria do risco administrativo. Nessa lógica, o Poder Público é responsabilizado por causa do risco que a atividade administrativa cria (Hupffer et al, 2012, p. 110), o que torna suficiente a existência do dano e do nexo causal para surgir o dever de indenizar. Segundo Cavalieri Filho, "é a forma democrática de repartir os ônus e encargos sociais por todos aqueles que são beneficiados pela atividade da Administração Pública” (2011, p. 11).

A redação do $§ 6^{0}$ do artigo 37 não faz distinção entre ações e omissões. Mas encontram-se entendimentos variados nos manuais de Direito Administrativo ${ }^{8}$ e em outras literaturas do Direito. De modo geral, há duas correntes. Uma delas afirma que a responsabilidade objetiva só é aplicada nos casos de ação estatal. Ao se tratar de omissão, o regime é o da responsabilidade subjetiva. Maria Sylvia Zanella Di Pietro e Celso Antônio Bandeira de Mello são alguns dos signatários desse grupo. Para eles, a obrigação do Estado de indenizar nos casos de omissão deve decorrer de conduta contrária ao Direito (ato ilícito), podendo ser culposa ou dolosa. Trata-se da teoria da culpa administrativa - também chamada de teoria da culpa do serviço, da falta de serviço ou da culpa anônima -, compreendida como uma evolução da responsabilidade subjetiva do Direito Civil, que foi o primeiro ramo do Direito a ofertar soluções para os casos de responsabilidade do Estado, afirma Elisa Ustárroz (2012, p. 72). Por essa teoria, o lesado deve demonstrar a ineficiência do serviço público, isto é, o serviço não funcionou, funcionou mal ou demorou em funcionar.

Nos casos de omissão estatal, para Celso de Mello (2008, p. 998), é preciso primeiro que exista a obrigação legal de impedir o dano, e culpa (negligência, imprudência ou imperícia) ou dolo (intenção de se omitir quando o Estado deveria ter atuado segundo um padrão de eficiência capaz de impedir o evento lesivo).

Na lição de Di Pietro, o Estado apenas pode ser responsabilizado se ele tinha o dever de agir e a possibilidade de evitar o dano. Para a autora, "não há como falar em responsabilidade objetiva em caso de inércia do agente público que tinha o dever de agir e não agiu, sem que para isso houvesse uma razão aceitável" (2011, p. 655). Mas ela defende que a vítima não precisa fazer prova da culpa do Estado; é o ente público que 
terá de demonstrar que agiu com diligência, utilizando todos os meios adequados e disponíveis. 0 ente público poderá argumentar que se não agiu foi porque tal atuação estaria acima do que seria razoável exigir. Se uma dessas hipóteses for comprovada, não haverá responsabilização (DI PIETRO, 2012, p. 656).

A outra corrente, por sua vez, defende o regime da responsabilidade objetiva como a regra do Direito brasileiro, abarcando ação e omissão. Pela teoria objetiva, a obrigação de indenizar pode ser causada por um ato lícito ou ilícito, bastando demonstrar o nexo causal, o dano e a conduta do agente público nessa qualidade para que a vítima seja indenizada. Ao Poder Público incumbe provar a inexistência de nexo causal.

Para Gandini e Salomão, a CF/88 não faz distinção entre atos comissivos e atos omissivos. Os autores afirmam:

Entende-se que o legislador brasileiro, muito bem informado, à época, da evolução do instituto, não teria recuado no tempo, estabelecendo a responsabilidade subjetiva apenas para os casos de conduta comissiva, retroagindo, no que tange à omissão, aos tempos da culpa civilística ou da faute du service, seria demasiado. Aliás, a responsabilidade objetiva já vinha consagrada no direito brasileiro desde a Constituição Federal de 1946 [art. 194]. Por que, então, o legislador constitucional, ao invés de avançar, teria preferido recuar, distinguido as duas condutas? Qual o fundamento legal e político, para a distinção? (2003, p. 219)

Também faz parte desse grupo Juarez Freitas, que afirma ser equivocada a ideia de que a responsabilidade estatal por omissão deva ter tratamento diverso do empregado nos atos comissivos. Para o jurista, a responsabilidade do ente público deve ser orientada conforme o princípio constitucional da eficácia imediata dos direitos fundamentais e o direito fundamental à boa administração (FREITAS, 2012, p. 2-5). Isso não significa responsabilizar o Estado em qualquer situação de inércia, mas, sim, naquelas que se observa desproporcionalidade. Isto é, a Administração agiu com demasia ou foi inoperante na consecução dos objetivos fundamentais da República (FREITAS, 2010, p. 67).

Um dos maiores receios dos juristas que são contrários à responsabilização objetiva do Estado por omissão é que o ente público torne-se um segurador universal de todos os danos sofridos pelos 
cidadãos. Isso porque, explica Celso de Mello, o Estado é responsável por prover todos os interesses da coletividade, podendo fazer com que qualquer ato lesivo causado por terceiro leve a vítima a sustentar que o serviço não funcionou (2008, p. 998). Porém, Juarez Freitas adverte que o regime da responsabilidade objetiva não significa a atribuição cega do dever indenizatório (FREITAS, 2010, p. 72), pois o Estado pode defenderse demonstrando elementos excludentes de responsabilidade, como culpa exclusiva da vítima, caso fortuito, força maior ou culpa de terceiro.

Sustentando argumento intermediário, encontra-se Sérgio Cavalieri Filho. Para ele, deve ser aplicada a teoria subjetiva quando se tratar de omissão genérica da Administração. 0 autor explica que omissão genérica refere-se àqueles casos que o dano não foi causado direta e imediatamente pela inação da atividade estatal, como fenômenos da natureza (chuvas torrenciais e inundações, por exemplo) ou atos praticados por terceiros (assaltos, furtos ou acidente de trânsito em via pública). Nessas situações, a vítima deverá provar que a falta do serviço gerou o prejuízo (2011, p 16). Mas, ao se tratar de omissão específica, o caso será regido pela teoria objetiva da responsabilidade. Trata-se daquelas situações que o Estado estava na condição de garante, porém, omite-se, criando um cenário propício para a ocorrência do evento danoso. Nesses casos, afirma Cavalieri Filho, a Administração tinha o dever específico de agir. Como exemplo, o autor cita o de estudante que morre afogada em bueiro aberto no pátio de escola pública (2011, p. 17).

Neste artigo, defende-se o regime da responsabilização objetiva do Poder Público, sobretudo ao se tratar de inércia diante de direitos fundamentais, como a saúde. Por outro lado, sabe-se que o SUS, atualmente, não dispõe de verba suficiente (seja pela limitação dos recursos, seja pela má gestão) para atender as várias demandas da população. Essas situações podem reduzir as chances de cura ou de melhora da qualidade de vida dos pacientes, gerando dano aos usuários. Por isso, acredita-se que a simples aplicação das regras da responsabilidade objetiva não é suficiente para caracterizar adequadamente a responsabilidade do Estado pela perda da chance. Significa dizer que se faz necessário estabelecer parâmetros para responsabilizar o ente público. Seguindo essa linha de raciocínio, a etapa seguinte deste trabalho abordará critérios para 
responsabilizar o Estado quando a usuária com câncer de mama não iniciar o tratamento oncológico em até 60 dias na rede pública de saúde.

\section{Universalidade do acesso ao tratamento contra o câncer de mama em até 60 dias $^{9}$}

Ao avaliar a distribuição de assistência médica nos Estados Unidos, Ronald Dworkin observou que há uma distribuição injusta desse serviço ${ }^{10}$. Isso levou o autor norte americano, na obra "A Virtude Soberana: a teoria e a prática da igualdade", à seguinte questão: "quanta assistência médica uma sociedade razoável deve tornar acessível a todos? Não podemos oferecer a todos a assistência médica que os mais ricos dentre nós podem comprar para si. Como decidir qual é o nível mínimo de assistência médica que a justiça exige que até os mais pobres tenham?" (DWORKIN, 2005, p. 431-432).

No ordenamento jurídico brasileiro, parte dessa resposta pode ser encontrada no artigo "O direito a prestações de saúde: complexidades, mínimo existencial e o valor das abordagens coletiva e abstrata”, escrito por Ana Paula Barcellos. A autora elencou dispositivos da CF/88 que esboçam o núcleo mínimo do direito à saúde: a prestação do serviço de saneamento (arts. 23, IX; 198, II; e 200 IV); o atendimento maternoinfantil (art. 227, § 1, I); as ações de medicina preventiva (art. 198, II); e as ações de prevenção epidemiológica (art. 200, II) (BARCELLOS, 2008, p. 142). Mas, para além do mínimo, que outras ações dessa área devem estar disponíveis para todos - e que continue honrando o ideal de igualdade?

Dworkin apresenta duas alternativas. A primeira é baseada no "princípio do resgate", que está ligado a um modelo de justiça presente há muito tempo na área médica. Esse princípio é composto por duas noções. A primeira afirma que a saúde e a vida são os bens mais valiosos, o que permite sacrificar "bens menores" em prol deles. A outra noção dispõe que a assistência médica deve ser distribuída com equidade. Significa que serviços médicos não podem ser negados àquele que necessita e que não tem como custeá-los. Desse modo, o país deve empregar tudo o que 
puder nessa área, até que não seja mais possível pagar nenhuma melhora na saúde do doente. Para o autor, essa prática é inviável, expondo:

Nenhuma sociedade sadia tentaria alcançar esse padrão, da mesma forma que uma pessoa sadia também não organizaria a própria vida segundo tal princípio. Nos últimos séculos, contudo, não houve uma lacuna tão grande entre retórica do princípio do resgate e o que era medicamente possível para a comunidade fazer. Agora, porém, que a ciência criou tantas formas caríssimas de assistência médica, é absurdo pensar que a comunidade continue tratando a vida como um bem fornecido a qualquer custo - mesmo que tornasse praticamente inútil a vida mais longa das pessoas $(2005$, p. 435).

Além disso, é provável que o pagamento indireto pela assistência médica - sobretudo quando se trata de uma rede pública de saúde torne os cidadãos "menos sensíveis" aos custos dos serviços. Segundo Dworkin: "Talvez as pessoas gastassem menos consigo mesmas ou com a família se tivessem de pagar do próprio bolso os custos reais, à custa de outros bens e oportunidades que talvez quisessem ter ou quisessem que a família tivesse" (DWORKIN, 2005, p. 436).

Há fortes indícios que a lógica do princípio do resgate não é viável no Brasil. Isso porque, além da divisão entre saúde e outras necessidades sociais, é preciso repartir o montante destinado à saúde entre os diversos pacientes que necessitam de variados tratamentos médicos.

A segunda alternativa apontada por Dworkin está relacionada ao “princípio do seguro prudente". Por esse princípio, a definição do nível justo de recursos destinados à saúde baseia-se nas decisões alocativas que pessoas prudentes fariam para si mesmas em condições ideais (2005, p. 437).

O referido autor descreve uma comunidade ideal, cuja assistência médica foi deixada à mercê de um mercado livre de seguros. Nessa sociedade, estão presentes três pressupostos: a distribuição de riquezas é a mais justa possível; há disponibilidade de informações acerca de custos, benefícios e efeitos colaterais de tratamentos; e inexistem informações sobre as possibilidades que cada pessoa ou grupo tem de apresentar determinada doença (FERNANDES, 2014, p. 127). As decisões acontecem num mercado livre: hospitais, médicos e indústrias farmacêuticas cobram 
o valor que quiserem. Nesse cenário, o governo não oferece assistência médica, pois as pessoas têm capacidade financeira suficiente para pagar pelos serviços que julgarem necessários.

Nessa situação, qual seria o comportamento das pessoas no momento de contratar o seguro de saúde? Qual seria a porção de recursos que essa sociedade ideal empregaria na assistência médica?

Segundo Dworkin, não há uma resposta precisa para essas perguntas. Entretanto, ele assegura que o valor empregado por essa comunidade seria a quantia moralmente apropriada. Por isso, não seria justo ofertar assistência médica aos que não contrataram o seguro. Em resumo: a distribuição justa é aquela que as pessoas bem informadas criam para si por meio de escolhas individuais, contanto que o sistema econômico e a distribuição da riqueza na comunidade também sejam justos (DWORKIN, 2005, p. 441).

Dworkin destaca que a prudência está relacionada a necessidades, a gostos, e à personalidade dos sujeitos. Contudo, é possível identificar alguns parâmetros que se enquadrariam na preferência da comunidade em geral. Um jovem de 25 anos, por exemplo, não contrataria, em regra, um plano de saúde que ofertasse tratamento de manutenção das funções vitais em caso de estado vegetativo persistente. Isso porque a quantia do prêmio seria muito elevada. Para o jovem, o valor desse tratamento caro seria melhor empregado se utilizado em outras formas de melhorar a sua vida consciente e real (DWORKIN, 2005, p. 441). Entretanto, o argumento da prudência apresenta exceções. Ao avaliar os riscos, algumas pessoas julgariam que vale a pena o grande sacrifício anterior.

Segundo o filósofo americano, um plano de saúde com base no que a maioria deseja e está disposta a pagar - e não um pequeno grupo - é a opção mais justa. A minoria decidida a gastar mais por atendimentos especiais deve fazê-lo por meio de um seguro complementar (DWORKIN, 2005, p. 444). Em termos reais, o seguro prudente se manifestaria por meio de políticas de saúde, em que haveria um sistema de impostos e de benefícios. 0 prêmio do seguro hipotético seria o que deve ser arrecadado por meio de tributos. Já a cobertura refletiria o que seria gasto com a redistribuição em forma de benefícios. 
No Brasil, os serviços que a comunidade quer e pode ofertar a todos universalmente são expressos por meio de escolhas dos representantes do Legislativo e do Executivo, de equipes multidisciplinares que compõem o SUS e, em algumas vezes, através da participação direta dos cidadãos. Nesse sentido, quando o Poder Legislativo elaborou a Lei 12.732/2012, estava afirmando que o acesso em até 60 dias ao tratamento médico seria possível (e) para todos.

Dessa forma, à luz do esquema do seguro prudente de Dworkin, propõe-se: se determinada assistência médica está prevista em lei é porque a comunidade, por meio de seus representantes - eleitos democraticamente - comprometeu-se a disponibilizá-la para qualquer cidadão que necessitar dela. De igual modo, a comunidade também se obrigou a arcar com os custos.

Além disso, se o cidadão brasileiro, em condições justas e ideais, fosse adquirir um plano de saúde para si ou para sua família, é bastante provável que ele adquiriria um plano que fornecesse acesso ao tratamento oncológico em tempo hábil. Isso porque teria conhecimento de que o câncer é uma doença com alta incidência, bem como saberia que quanto mais precoce for o diagnóstico e o início do tratamento oncológico, maiores são as chances de cura ou de prolongamento da vida.

Entende-se que o Estado não pode ser responsabilizado se não há uma política que o obrigasse a atender a todos os indivíduos na mesma situação. Significa dizer: ao requerer a reparação pela perda da chance de cura ou de sobrevida, é fundamental que a medida indicada para o caso estivesse contemplada nos protocolos do SUS. Portanto, a responsabilidade do Estado pela perda da chance está condicionada à existência de um serviço de saúde universal. Com isso, reafirma-se o princípio da universalidade, que rege o SUS ${ }^{11}$.

Baseando-se nos ensinamentos sobre o princípio do seguro prudente, de Ronald Dworkin, a escolha dessa assistência reflete quanto de recursos para a área da saúde a comunidade está disposta a gastar. No Brasil, ofertar o primeiro tratamento médico ao paciente dentro de 60 dias após o diagnóstico foi uma escolha da nação - representada pelo Poder Legislativo - que entende ser esse serviço essencial para todos. Portanto, o descumprimento da lei é uma das condições que 
enseja o dever do Estado indenizar a vítima, in casu, a paciente com câncer de mama.

\section{Acessibilidade ao tratamento médico frente às barreiras geográficas}

Na estrutura da atenção básica predominam unidades de pequeno porte distribuídas no local onde as pessoas vivem e trabalham; os cuidados necessários "vão" até o usuário. Na atenção especializada, em contrapartida, são os usuários que devem se deslocar até o local onde são realizados os serviços (SOLLA; CHIORO, 2012, p. 569-550). Tais serviços, em regra, não são oferecidos em municípios do interior do estado. Tratase, portanto, de um nível de saúde fisicamente centralizado. A maioria deles localiza-se nas capitais ou em regiões centrais. Por essa razão, afirma Souza et al., o lugar dessa estrutura pode ser um elemento que contribua para o atraso do início do tratamento oncológico, podendo, em alguns casos, resultar no abandono do tratamento porque o centro de referência é geograficamente muito distante da residência da paciente e/ou porque o deslocamento gera elevado custo econômico (2015, p. 2).

Conforme as diretrizes do SUS, deve-se garantir aos usuários acesso aos serviços especializados no município que residem. Entretanto, no plano da realidade, em muitos casos, o paciente terá que buscar centros de referência intermunicipais ou até mesmo interestaduais. 0 que não for resolvido em nível de atenção básica será referenciado (encaminhado) para os serviços de maior complexidade tecnológica: ambulatórios de especialidades, serviços de diagnóstico, terapêutico, e atenção hospitalar. Portanto, "barreiras geográficas" também é um fator que pode prejudicar as chances de cura ou de sobrevida da paciente com câncer de mama donde surge o segundo critério a ser analisado: em que medida o fator geográfico retardou o acesso ao centro de referência oncológico, no qual a paciente com câncer começaria seu tratamento médico?

Por barreira geográfica entende-se a resistência que o espaço físico impõe ao deslocamento de potenciais usuários do SUS. Segundo Gonçalves et al., as barreiras geográficas podem estar relacionadas ao 
deslocamento para outra cidade e à dificuldade de acesso ao transporte fornecido pela Secretaria Municipal de Saúde (2014, p.396). A distância percorrida também deve ser levada em consideração, pois o tratamento exigirá que a paciente realize repetidas visitas ao centro de referência para consultas e aplicações terapêuticas. Nesse sentido, durante o período do tratamento oncológico, a necessidade de meio de transporte pode se tornar um obstáculo para as usuárias do SUS com câncer de mama, na medida em que os serviços de maior densidade tecnológica estão centralizados nas capitais e grandes cidades. Conforme o pesquisador e médico pernambucano, Christiano Paiva, a maioria das pacientes com neoplasia mamária, que fez parte de seu estudo, relatou não ter veículo próprio, dependendo, portanto, de transporte fornecido pelas prefeituras, de transporte público ou da ajuda de amigos ou familiares (2013, p. 73).

Pesquisa realizada na Colômbia, citado por Gonçalvez et al., indicou a necessidade de se deslocar para outra cidade como um dos principais empecilhos para intervenções terapêuticas (2014, p. 398). No Brasil, os obstáculos regionais são um problema que atinge todos os níveis de serviços do SUS. Entretanto, essa questão é mais intensa na Atenção de Média e de Alta Complexidade porque demandam maior emprego de tecnologias, de estrutura física e de profissionais especializados. Esse cenário compromete um desfecho favorável para a paciente com neoplasia mamária.

Portanto, ao avaliar se o Estado causou a perda da chance da paciente com câncer de mama, é preciso averiguar se a residência dela era distante do centro de referência onde foi aplicado o tratamento médico necessário. Após, deve-se apurar se a mesma tinha meios próprios para se dirigir até o hospital; em caso negativo, se havia transporte público fornecido pela Secretaria de Saúde do município.

Ao não providenciar locomoção adequada em tempo oportuno, o ente público prejudica o tratamento oncológico da paciente. Considera-se o presente parâmetro como fundamental para o bom desenvolvimento do tratamento médico da usuária. Sabe-se que uma quantia considerável de usuárias do SUS não detém recursos financeiros suficientes para custear transporte, alimentação e, em alguns casos, estada na cidade do centro 
especializado. Por vezes, as pacientes acabam abrindo mão de fazer o tratamento oncológico para não prejudicar o orçamento familiar.

\section{Tratamento contra o câncer de mama materialmente possível}

No Brasil, percebe-se uma tendência a criar leis para descrever direitos em seus mínimos detalhes, ou para reforçar de maneira mais específica um direito já existente - como se o texto legal, por si só, pudesse solucionar todos os problemas. O lado positivo dessa "prática" é que, na teoria, novas garantias são pormenorizadamente asseguradas. De outra parte, isso pode gerar excesso de expectativas nos cidadãos, pois, em alguns casos, o Executivo não consegue dar cumprimento satisfatório e/ou pleno àquela criação legislativa, frustrando a comunidade que esperava do Estado a disponibilidade de determinado serviço.

Com esse argumento, não se defende a interrupção do desenvolvimento de novas leis que asseguram direitos fundamentais sociais, mas uma maior interlocução entre os poderes, a fim de que determinadas propostas legislativas sejam mais coerentes com a realidade, e para que o Executivo possa fazer uma gestão mais eficiente dos recursos disponíveis, tornando a eficácia dos direitos a mais ampla possível. Nessa linha de raciocínio, a proposta do terceiro parâmetro é avaliar a capacidade do Estado realizar a previsão legal por meio (i) do orçamento público e do contexto financeiro do país, (ii) da disponibilidade de tecnologias com eficácia comprovada e segura para uso em seres humanos e (iii) da disponibilidade de profissionais hábeis para realizar o serviço, bem como a existência de estrutura física para prestá-lo.

Ao se tratar do direito à saúde no Brasil, é preciso que haja um comportamento financeiro racional, isto é, um equilíbrio entre previsão orçamentária e previsão constitucional, pois o conteúdo do direito à saúde - ensinam Avelãs Nunes e Scaff - sempre dependerá dos recursos financeiros constantes no orçamento do Estado (2011, p. 40). Esse documento espelha as decisões políticas tomadas na alocação das receitas públicas, que serão aplicadas em políticas públicas. Em outros 
termos, os créditos orçamentários financiam os meios necessários para a prestação de serviços de saúde. Mas também fixam os limites da oferta (CANOTILHO; VITAL, 1991, p. 171).

No direito brasileiro, a escolha sobre os gastos públicos é realizada pelo Poder Legislativo por intermédio do sistema orçamentário. Nesse procedimento é exercido controle sobre as despesas públicas, bem como é fixado o nível de prioridade que a efetivação de determinada garantia tem para a comunidade em certo período. Portanto, o orçamento que o Estado dispõe para tornar efetivo o direito à saúde é uma questão de ordem política de responsabilidade dos representantes democraticamente eleitos. ${ }^{12}$

Em resumo, ao avaliar se o Estado deve ser responsabilizado pela perda da chance, é preciso levar em consideração a quantia financeira que o parlamento destinou para as políticas de saúde, e a atual conjuntura econômica do país. Após verificar que determinada assistência médica foi escolhida pela comunidade para ser oferecida universalmente (critério 1) e se a paciente com câncer de mama conseguiu chegar ao centro de saúde especializado em tempo hábil (critério 2), deve-se investigar quanto do serviço oncológico, especialmente contra o câncer de mama, pode ser distribuído para todas que venham a necessitar dele, segundo a disposição orçamental.

Outros fatores também estão vinculados à possibilidade material de executar o serviço, como a disponibilidade de tecnologias com eficácia comprovada e seguras para consumo dos seres humanos. Muitas pesquisas em torno da cura do câncer ou de novos medicamentos para melhorar a qualidade de vida do paciente oncológico estão em andamento. Os tratamentos fornecidos pelo SUS são adequados às regras da Anvisa, que, em regra, autoriza apenas aqueles com eficácia e segurança comprovada. Isso quer dizer que a vítima não fará jus à indenização quando ela afirmar que perdeu a chance de cura ou de prolongamento da vida porque o Estado não forneceu tratamento experimental ou uma terapêutica que, por motivo justificável, não integra a lista do SUS.

Um exemplo de tratamento oncológico não fornecido pelo SUS, mas que representa no senso comum a cura das mazelas do câncer é a fosfoetanolamina sintética - popularmente conhecida como "pílula 
do câncer" -, uma droga distribuída gratuitamente, desde 1990, pelo Instituto de Química de São Carlos da Universidade de São Paulo às pessoas com câncer. Alguns enfermos afirmaram sentir-se melhor após o seu uso - algumas até mesmo relataram cura. Em 2014, em razão da falta de testes, de pesquisas e de registro na Anvisa, a Universidade de São Paulo proibiu a distribuição do composto.

Apesar de não haver resultados conclusivos sobre a segurança e eficácia da droga, o Congresso Nacional aprovou a distribuição e uso da droga, por meio da Lei 13.269/2016. A Associação Médica Brasileira (AMB) ajuizou ação declaratória de inconstitucionalidade (ADI 5501). 0 Plenário do Supremo Tribunal Federal, em sede de liminar, por maioria dos votos, suspendeu a liberação e o uso da fosfoetanolamina. Apesar da suspensão, o governo federal vem investindo em pesquisas para verificar a eficácia e segurança da substância. ${ }^{13}$

Propõe-se, então, que o tratamento oncológico não fornecido no prazo da lei deva ser aquele que (i) tenha eficácia e segurança comprovada, (ii) esteja disponível no mercado para aquisição e (iii) faça parte dos protocolos do SUS ou, se não integrante, que disponha de uma boa relação custo-benefício - podendo inclusive ser posteriormente adicionado à lista de procedimentos ofertados pela rede pública. Do contrário, muitos demandarão contra o Estado alegando que perderam a chance de cura ou sobrevida porque determinado tratamento médico inovador contra o câncer de mama não foi ofertado à vítima.

Nessa linha de argumentação, destaca-se a lição de Fernando Scaff. Para ele, uma das características dos direitos sociais é a progressividade, ou seja, essas garantias não são disponibilizadas de uma vez (NUNES; SCAFF, 2011, p. 98). Elas são implementadas à prestação. Em termos de direito à saúde, não é possível executar plenamente o disposto no art. 196 da CF. Algumas das razões para isso, explica Scaff, têm a ver com o desenvolvimento científico e tecnológico da Medicina - que paulatinamente vem trazendo novas respostas aos problemas de saúde existentes - e com a limitação dos recursos públicos disponíveis (NUNES; SCAFF, 2011, p. 98)

É preciso verificar também se há profissionais especializados e estrutura física que comportem a ação prevista na lei, pois “a característica 
de acesso mais importante é a disponibilidade ou presença física de serviços, equipamentos e recursos humanos, que representa condição absolutamente necessária à utilização" (TRAVASSOS; CASTRO, 2012, p. 186). Em $2011^{14}$, ao realizar o Relatório de Auditoria Operacional sobre a Política Nacional de Atenção Oncológica, o Tribunal de Contas da União constatou que a carência de profissionais especializados é um dos fatores que contribui para um atendimento menos célere na atenção oncológica (BRASIL, 2011, p. 44). É o caso de médicos patologistas, que são os responsáveis pela análise dos tecidos coletados em biópsia e emissão de parecer de laudo patológico. Esses profissionais são fundamentais para o diagnóstico e para posterior planejamento do tratamento médico.

De igual modo, a existência de estrutura física adequada também é essencial para o acesso aos serviços oncológicos. 0 processo de infraestrutura desses serviços acontece basicamente por meio de aquisição de equipamentos e da realização de obras civis. Essa estruturação demanda investimento de quantia financeira vultosa. Os locais onde a radioterapia é realizada, por exemplo, carecem de instrumentos de alto custo e da realização de obras de engenharia especial. 0 Tribunal de Contas da União constatou que

[...] a rede de atenção oncológica não se mostra suficiente para atender a toda a demanda dos pacientes por diagnóstico e tratamento de câncer. (...) Na época do levantamento existiam 264 estabelecimentos habilitados, sendo que alguns destes possuíam capacidade instalada para determinados tipos de tratamento equivalente a mais de um Unacon ou Cacon. 0 levantamento do Inca evidencia déficit na capacidade instalada de cirurgia, de 44 unidades de atendimento; de quimioterapia, de 39 unidades de atendimento; e de radioterapia de 135 unidades de atendimento ou equipamentos (BRASIL, 2011, p. 30)

Ainda segundo essa Corte administrativa, constatou-se que Rio Grande do Sul, São Paulo e Rio de Janeiro são os estados onde se identifica maior carência de quantidade de equipamentos de radioterapia. A falta de recursos, porém, não é a única causa para isso. Apurou-se que, em certas unidades de saúde, os aparelhos de radioterapia estavam encaixotados por mais de cinco anos; em outras, havia excesso de tempo para consertar os equipamentos danificados (BRASIL, 2011, p. 30). 
De todo o exposto, esse parâmetro tinha como linha condutora a seguinte dúvida: a atividade em que a Administração Pública se omitiu era materialmente possível? Em princípio sim, pois na deliberação do projeto de lei que originou a Lei 12.732/2012 é possível observar que o prazo de 60 dias foi um acordo firmado entre Legislativo e Executivo. Além disso, já se passaram quase cinco anos da entrada em vigor dessa regra jurídica, e não se observa uma diminuição no tempo de espera para acessar o primeiro tratamento - conforme dados do Integrador RHC.

Portanto, é necessário que o Executivo e o Legislativo estabeleçam um diálogo que verse sobre questões econômicas, tecnológicas e de recursos humanos que a lei demandará para ser executada, de modo que seja elaborado um plano para tornar os efeitos do comando legal o mais amplo possível. A distribuição é característica do Estado Social, porém, conforme adverte Manuel García-Pelayo, para que haja uma distribuição permanente de algo é preciso ter poder de disposição sobre este algo, bem como garantir sua produção e reprodução (2009, p. 23). Além disso, a distribuição deve ser operacionalizada conforme a realidade fática do país.

\section{CONCLUSÃO}

Os avanços na medicina vêm ampliando as chances de cura ou de maior sobrevida das pacientes com câncer. Em termos de saúde pública, para que esse progresso produza efeitos positivos para as usuárias do SUS com câncer de mama, são necessárias maiores ações governamentais. Essa medida torna-se mais relevante quando se analisa o número de óbitos causado por essa patologia.

Estudos demonstram que as taxas de incidência estão aumentando em países desenvolvidos e os índices de mortalidade estão diminuindo. Já em países em desenvolvimento, os índices de incidência e de mortalidade estão cada vez mais altos. No Brasil, atualmente, a cada 100 mil mulheres, 12,1 morrem em razão do câncer de mama. Pode-se apontar o diagnóstico tardio como um dos fatores para esse índice de mortalidade, pois à medida que a doença é detectada em fase avançada, menores são as chances de cura ou de prolongamento da vida. Cerca de $60 \%$ das brasileiras com 
câncer de mama são diagnosticadas em estádio avançado ou em fase metastática (quando as células cancerígenas espalham-se para outros órgãos; geralmente pulmões, ossos ou fígado). Essa realidade torna um tratamento médico célere mais fundamental ainda. Contudo, há usuárias da rede pública que não conseguem receber a aplicação terapêutica no prazo legal. Por isso, esse estudo teve por finalidade tentar elaborar parâmetros para responsabilizar civilmente o Estado pela perda da chance de cura ou de sobrevida das pacientes com câncer de mama.

Para alcançar esse objetivo, averiguou-se, inicialmente, qual foi a taxa de efetividade da mencionada regra jurídica. Buscaram-se dados junto ao Integrador RHC. Constatou-se que a forma de ingresso no centro especializado é fator importante no tempo de espera para receber a primeira aplicação terapêutica. Usuárias do SUS que pertençam a uma região que não dispõe de estrutura e recursos adequados para realizar exames necessários para confirmar o diagnóstico de câncer são encaminhadas ao centro de referência e conseguem, após diagnóstico, iniciar o tratamento médico de forma mais rápida, quando comparadas àquelas que, após diagnóstico na rede de média complexidade, são referenciadas ao hospital adequado para tratamento.

0 atraso no início do tratamento pode diminuir a taxa de cura ou de sobrevida da paciente oncológica. Os juristas civilistas apontam essa situação como um prejuízo que merece ser reparado. Trata-se do dano pela perda da chance. Entretanto, para que seja possível a responsabilização do ente estatal, acredita-se ser necessário observar três condições, as quais podem ser verificadas procedendo-se aos seguintes questionamentos:

(a) A Lei 12.732/2012 foi uma escolha prudente da sociedade brasileira, isto é, trata-se de um serviço necessário e que deve estar disponível para todos que dele carecerem? É uma assistência médica que os cidadãos dispuseram-se a custear? Entende-se que sim, pois o Legislativo deliberou sobre a indispensabilidade de um acesso célere ao tratamento contra o câncer e acordou com o Governo o prazo de 60 dias, o qual afirmou ser viável.

(b) Para as pacientes com câncer de mama que habitam em localidades afastadas e que não dispõem de meio de transporte para se 
dirigir até o centro de referência, foi ofertado transporte público e gratuito pela Secretaria de Saúde do município em tempo hábil? Se a resposta for negativa, isso constitui mais um elemento que reduz as taxas de cura da usuária do SUS com tumor na mama, causada pela inércia estatal.

(c) Com os recursos financeiros dispostos no orçamento público - documento elaborado pelos representantes do povo - era possível financiar o tratamento médico indicado para tratar o câncer de mama da paciente? A terapêutica fazia parte da lista de procedimentos do SUS, era um tratamento eficaz e seguro para o uso em seres humanos? Para os casos em que o tratamento não foi contemplado pela Tabela do SUS, tratava-se de procedimento com eficácia comprovada - e não de um procedimento experimental? Para realizar a aplicação terapêutica, havia estrutura física e profissionais habilitados na região para suprir a demanda? Se a respostas para esse item "c" forem todas positivas, estarse-á diante de mais indícios para a responsabilização do Estado.

A proposta de responsabilização objetiva do Estado pela perda da chance, aqui apresentada, não tem a pretensão de tornar o ente público um segurador universal, mas de atribuir a responsabilidade nos casos que ele descumpriu desproporcionalmente uma prestação que ele se comprometeu. Além disso, esses critérios não significam uma solução para todos os casos de perda da chance, pois o direito não é matemático. Em outras palavras, os critérios 1, 2 e 3 não fazem parte de uma espécie de equação que se aplica ao caso concreto e se obtém a resposta. É preciso conectar o problema real com a solução apropriada, a qual deve ter sempre a CF/88 como norte.

\section{NOTAS}

1 Atualmente, corrupção e saúde estão no mesmo patamar de preocupação dos brasileiros, conforme apuração realizada pelo Datafolha em junho de 2017.

2 Desconsiderando o câncer de pele não melanoma.

3 Extensão anatômica da doença. É sinônimo de estágio da doença.

4 É importante destacar que as informações contidas nessa plataforma não são $100 \%$ provenientes de unidades de saúde do SUS; hospitais privados também inserem dados no RHC. Em razão de o presente estudo ter como foco apenas as usuárias do SUS, questionou-se ao INCA, via correio eletrônico, se havia uma seleção somente de hospitais públicos. A Divisão de Vigilância e Análise de Situação (setor do INCA) respondeu que não há distinção. Afirmou, entretanto, que a maioria dos dados contidos no Integrador RHC é proveniente de hospitais habilitados pelo SUS no nível de Alta Complexidade. 
5 São as pacientes são que chegam ao hospital de referência sem diagnóstico e sem tratamento. Apenas com suspeita da doença.

6 São as pacientes encaminhadas ao hospital com diagnóstico, contudo, ainda não iniciaram o tratamento médico. Em regra, as pacientes deveriam chegar ao hospital de referência com diagnóstico confirmado ou com presunção que indique fortemente a presença de tumor para ser confirmado (INCA, 2010, p. 68-69). Porém, por uma série de deficiências da rede pública, a usuária é encaminhada diretamente para a unidade especializada.

7 Na atual pesquisa não se investigou os motivos que levam a essa disparidade.

8 Doutrina por vezes citada nas decisões de Tribunais Superiores, a título de exemplo: REsp 1095309/AM; RMS 23587/RJ e REsp 1159935/RJ.

90 primeiro critério listado tem como base o princípio do seguro prudente, desenvolvido por Ronald Dworkin. Esse princípio é uma adaptação da teoria do seguro hipotético, o qual não será abordado. Isso porque a teoria do seguro prudente é específica e adequada para o presente tema.

10 Uma distribuição injusta dos serviços de saúde também foi constatada no Brasil por Felipe Nogueira Fernandes. Os dados levantados pelo autor foram publicados no artigo "O método do seguro prudente de Ronald Dworkin e o gasto público agregado em saúde no Brasil" (2014).

11 Antes da criação e da implantação do Sistema Único de Saúde - SUS - o regime da saúde pública no Brasil estava baseado nas regras do Instituto Nacional de Assistência Médica da Previdência Social - Inamps. Por esse sistema, as ações de saúde tinham como público alvo apenas os trabalhadores formais, isto é, aqueles com carteira assinada - e seus dependentes. Desta forma, parcela significativa da população brasileira, à época, ficava sem assistência médica, dependendo, em muitos casos, de organizações filantrópicas (ANDRADE; ANDRADE, 2010, p. 66). Portanto, a assistência médica era fornecida por meio de caridade para essas pessoas. Mas a Constituição Cidadã, em 1988, alterou a lógica do serviço público de saúde. Este direito social torna-se de todos, passando a ser dever do Estado fornecê-lo. A saúde pública desenvolve-se por meio do SUS, que é o conjunto de ações e serviços de saúde à disposição da população brasileira, sob a gestão do poder público (União, estados, DF e municípios). A Lei 8.080/90 disciplina as condições para a promoção, proteção e recuperação da saúde, a organização e o funcionamento dos serviços correspondentes. Ela estabelece que a assistência médica seja prestada por órgãos e instituições públicas federais, estaduais e municipais, da administração direta e indireta, bem como por fundações mantidas pelo governo. A iniciativa privada, diz a lei, pode participar do SUS, porém, em caráter complementar. O SUS rege-se pelos princípios elencados no art. $7^{\circ}$ da Lei 8.080/90: universalidade de acesso aos serviços de saúde em todos os níveis de assistência; integralidade de assistência, entendida como conjunto articulado e contínuo das ações e serviços preventivos e curativos, individuais e coletivos, exigidos para cada caso em todos os níveis de complexidade do sistema; preservação da autonomia das pessoas na defesa de sua integridade física e moral; igualdade da assistência à saúde, sem preconceitos ou privilégios de qualquer espécie; direito à informação, às pessoas assistidas, sobre sua saúde; divulgação de informações quanto ao potencial dos serviços de saúde e a sua utilização pelo usuário; utilização da epidemiologia para o estabelecimento de prioridades, a alocação de recursos e a orientação programática; participação da comunidade; descentralização político-administrativa, com direção única em cada esfera de governo. Pelo princípio da universalização, objetivou-se romper com a lógica histórica dualista em que, de um lado estava a assistência médica individual prestada aos trabalhadores formais, que contribuíam diretamente com a previdência social; e, por outro lado, os que não pertenciam formalmente ao mercado de trabalho e recebiam serviços de saúde através de filantropia (SOUSA, 2014, p.3). Entretanto, nota-se, atualmente, que, apesar de haver assistência médica gratuita e universal, parte da população brasileira tem optado por planos de saúde, pois consideram o tempo de espera para receber atendimento muito longo ou a qualidade do serviço ruim, por exemplo. Com isto, há uma migração significativa de brasileiros para a assistência médica privada. De modo geral, a saúde suplementar (planos de saúde e saúde privada) é utilizada pela classe média e alta, enquanto que o SUS tornou-se um sistema focalizado, que presta assistência aos mais pobres, os quais não têm outra opção, a não ser enfrentar longas filas de espera por consultas ou outros procedimentos médicos. Portanto, nas condições atuais, o caráter universal do sistema desaparece. 0 próprio governo, ao ofertar saúde suplementar aos 
seus servidores, confessa a precariedade e a não universalidade do serviço público de saúde. 0 critério da universalização, com base na teoria de Dworkin, reforça o princípio da universalização do SUS, porém, através de uma abordagem mais lógica e eficiente, pois traz a ideia de elencar ações e serviços de saúde que a própria população adquiriria para si, caso tivesse que compra-los diretamente. Ao que parece, em certos casos, durante a elaboração de determinado texto legal, no Brasil, deixa-se de lado questões importantes, como orçamento público e planejamento viável de execução do serviço. No Canadá, o sistema de saúde é público. Um dos princípios que o rege é a universalidade. Entretanto, a universalidade da rede não significa acesso de todos a todo tipo de serviço médico. Lá, existe um rol de assistência médica que é oferecido universalmente, os quais foram implantados gradualmente. 0 acesso a medicamentos, a serviços odontológicos e oftalmológicos, por exemplo, não são ofertados à população canadense na rede pública, exceto quando se trata de idosos e crianças (SOUSA, 2014, p.3).

12 Há quem defenda que, apesar de o orçamento ter importância significativa, o mesmo não pode ser usado como um instrumento bloqueador da efetividade dos direitos fundamentais. É o caso de Paulo de Tarso Brandão (2007). De fato, o orçamento público não pode ser sempre usado como forma de defesa da Administração Pública quando esta for demandada por não efetivar direitos fundamentais sociais. Porém, não se pode desconsiderar que os recursos financeiros são limitados e que escolhas devem ser feitas a fim de garantir ao maior número possível de pessoas o acesso aos bens e serviços produzidos.

13 É o caso da pesquisa realizada pelo Centro de Inovação e Ensaios Pré-Clínicos (Cienp), a requerimento do governo federal e financiada pelo Ministério da Ciência, Tecnologia, Inovações e Comunicações (MCTIC). Nesse estudo, células tumorais que causam câncer de pele em seres humanos foram aplicadas em camundongos. Após o $12^{\circ}$ dia do implante, os animais foram divididos em três grupos. 0 primeiro recebeu doses da fosfoetanolamina de $200 \mathrm{mg} / \mathrm{kg}$; o segundo, $500 \mathrm{mg} / \mathrm{kg}$. 0 terceiro grupo, porém, foi tratado com Cisplatina - medicamento reconhecido e utilizado há mais de 30 anos no combate a tumores - na frequência de três vezes por semana. Apuraram-se os seguintes resultados: a dose de $500 \mathrm{mg} / \mathrm{kg}$ de fosfoetanolamina sintética reduziu em $34 \%$ o tamanho do tumor. 0 grupo que recebeu a dose de $200 \mathrm{mg} / \mathrm{kg}$ da mesma substância não teve uma diminuição no tamanho do tumor; pelo contrário, o tamanho aumento 14 vezes em relação ao primeiro dia de tratamento. A Cisplatina, por fim, apresentou uma redução de 68\% (CENTRO DE INOVAÇÃO E ENSAIOS PRÉ-CLÍNICOS, 2016).

14 Último documento oficial publicado pelo TCU acerca do desenvolvimento da PNAO.

\section{REFERÊNCIAS}

ANDRADE, Elizabeth Nogueira de; ANDRADE, Edson de Oliveira. O SUS e o direito à saúde do brasileiro: leitura de seus princípios, com ênfase na universalidade da cobertura. Revista Bioética, Brasília, v. 18, n. 1, p. 61-74, 2010.

BARCELLOS, Ana Paula de. O direito a prestações de saúde: complexidades, mínimo existencial e o valor das abordagens coletiva e abstrata. Revista da Defensoria Pública, São Paulo, v. 1, n. 1, p. 133-160, jul./dez. 2008.

\section{BARROS, ALFREDO CARLOS DE, et al. Diagnóstico e tratamento do câncer} de mama. Disponível em: <http://s3.amazonaws.com/academia.edu. documents/40511193/024.pdf?AWSAccessKeyId=AKIAJ56TQJRTWSMTNPE A\&Expires=1477953898\&Signature=8us7UdHMUI4DLEg7eo\%2BNT3ve8zA\% 
3D\&response-content-disposition=inline $\% 3 \mathrm{~B} \% 20$ filename\%3DDiagnostico_e_ Tratamento_do_Cancer_de_Ma.pdf>. Acesso em: 31 out. 2016.

BRANDÃO, Paulo de Tarso. Falta de recursos do estado, direitos fundamentais e escolhas democráticas. In: COUTINHO, Jacinto Nelson de Miranda; MORAIS, José Luis Bolzan de; STRECK, Lenio Luiz. Estudos Constitucionais. Rio de Janeiro: Renovar, 2007.

BRASIL. Lei 12.732, de 22 de novembro de 2012. Dispõe sobre o primeiro tratamento de paciente com neoplasia maligna comprovada e estabelece prazo para seu início. Disponível em: <http://www.planalto.gov.br/ccivil_03/_ato20112014/2012/lei/112732.htm.> Acesso em: 01 jul. 2015.

BRASIL. Projeto de lei no 3.887-b, de 1997 (Do Senado Federal). Discussão, em turno único, do Projeto de Lei no 3.887-B, de 1997, que dispõe sobre o tratamento medicamentoso da dor em pacientes portadores de neoplasias comprovadas, por meio de entorpecentes, e dá outras providências. Diário da Câmara dos Deputados, Brasília, DF, 6 jun. 2012. Disponível em: < http://imagem.camara. gov.br/Imagem/d/pdf/DCD06JUN2012.pdf\#page=>. Acesso em: 10 jul. 2016.

BRASIL. Tribunal de Contas da União. Política Nacional de Atenção Oncológica. Relator Ministro José Jorge. Brasília: TCU, 2011.

CANADIAN INSTITUTE FOR HEALTH INFORMATION. Wait times tables - A comparison by province, 2010. Disponível em: < https://secure.cihi.ca/free_ products/wait_times_tables_2010_e.pdf>. Acesso em: 10 jul. 2016.

CANOTILHO, José Joaquim Gomes; VITAL, Moreira. Fundamentos da Constituição. Coimbra: Coimbra Editora, 1991.

CAVALIERI FILHO, Sérgio. Responsabilidade civil objetiva e subjetiva do Estado. Revista EMERJ, Rio de Janeiro, Vol. 14, n. 55, p. 10-20, jul./set. 2011.

CENTRO De Inovação e Ensaios Pré-Clínicos. Avaliação da atividade da fostoetanolamina sintética (USP-SÃO CARLOS) em modelo de tumor xenográfico de melanoma humano em camundongos. 2016, $25 \mathrm{f}$.

DI PIETRO, Maria Sylvia Zanella. Direito Administrativo. 24. ed. São Paulo: Atlas, 2011. 
DWORKIN, Ronald. A virtude soberana: a teoria e a prática da igualdade. São Paulo: Martins Fontes, 2005.

FERNANDES, Felipe Nogueira. 0 método do seguro prudente de Ronald Dworkin e o gasto público agregado em saúde no Brasil. In: CIARLINI, Alvaro Luis. Temas de jurisdição constitucional e cidadania: linguagem, racionalidade e legitimidade das decisões judiciais. Brasília: IDP, 2014, v. 2.

FOLHA DE SÃO PAULO. Para 6 em cada 10 brasileiros, saúde no país é péssima, out. 2015. Disponível em: < http://www1.folha.uol.com.br/ cotidiano/2015/10/1693244-para-6-em-cada-10-brasileiros-saude-no-paise-pessima.shtml >. Acesso em: 25 maio 2016.

FREITAS, Juarez. Contra a omissão inconstitucional: reexame inovador da responsabilidade do Estado. Revista do Ministério Público do RS, 2010, Porto Alegre, 66, p. 65-78, maio/ago. 2010.

FREITAS, Juarez. Por uma hermenêutica superadora da omissão inconstitucional nas políticas públicas. In: FREITAS, Juarez; TEIXEIRA, Anderson Vichinkeski (org.). Comentários à jurisprudência do STF: direitos fundamentais e omissão inconstitucional. Barueri: Manole, 2012.

GANDINI, João Agnaldo Donizeti; SALOMÃo, Diana Paola da Silva. A responsabilidade civil do Estado por conduta omissiva. Revista de Direito Administrativo, São Paulo, v. 232, p. 199-230, abr./jun. 2003.

GARCÍA-PELAYO, Manuel. As transformações do estado contemporâneo. Rio de Janeiro: Forense, 2009.

GONÇALVES, Leila Luiza Conceição et al. Barreiras na atenção em saúde ao câncer de mama: percepção de mulheres. Revista da Escola de Enfermagem da USP, São Paulo, v. 48, n. 3, p. 394-400, jun. 2014.

HUPFFER, Haide Maria et al. Revista Direito GV, São Paulo, v.ı8, n. 1, p. 109-129, Jan./Jun. 2012.

INCA. Estimativa 2014: incidência de câncer no Brasil. Rio de Janeiro: INCA, 2014. 
INCA. Estimativa 2016: incidência de câncer no Brasil. Rio de Janeiro: INCA, 2015.

INCA. Registros hospitalares de câncer: planejamento e gestão. 2. ed. Rio de Janeiro: INCA, 2010.

KAERCHER, Alessandra et al. Registro Hospitalar de câncer em um centro de referência no Sul do Brasil: análise dos diagnósticos ao longo de 7 anos. Revista Brasileira de Oncologia Clínica, Belo Horizonte, v. 10, n. 37, p. 103-107, jul./ set 2014.

LIMBERGER, Têmis. Cibertransparência. Informação pública em rede e a concretização dos direitos sociais: a experiência dos municípios gaúchos. Quaestio Iuris, Rio de Janeiro, v.8, n. 4, Número Especial, 2015, p. 2651-2669.

MELLO, Celso Antônio Bandeira de. Curso de Direito Administrativo. 25. ed. São Paulo: Malheiros, 2008.

MINAS GERAIS. Tribunal de Justiça. Câmara Cível, 8ạ. Apelação Cível no 1.0249.08.001824-8/001. Relator: Desembargador Elpídio Donizetti. Julgado em 22 nov. 2011.Disponivel em: <http://www4.tjmg.jus.br/juridico/sf/proc_ complemento.jsp?comrCodigo $=249 \&$ numero $=1 \&$ listaProcessos $=08001824>$ Acesso em: 15 out. 2014.

NUNES, António José Avelãs; SCAFF, Fernando Facury. Os tribunais e o direito à saúde. Porto Alegre: Livraria do Advogado, 2011.

OJEDA, Felipe Varela. Acceso a la información, transparencia y rendición de cuentas en el presupuesto para el VIH/sida en México. El caso del programa presupuestario "Prevención y atención del VIH/sida y otras ITS". In: LACHENAL, Cécile; RUIZ, Ana Joaquina (Coord.). Derecho de acceso a la información. La visión de los usuarios. Barcelona: Gesida Editorial, 2013.

PAIVA, Christiano José Kühl de. Câncer de mama no Hospital de Câncer de Pernambuco: perfil sociodemográfico e aspectos relacionados ao atraso no diagnóstico e tratamento. 2013. 102 f. Dissertação de Mestrado (Mestrado Profissional em Saúde Pública) - Centro de Pesquisas Aggeu Magalhães, Fundação Oswaldo Cruz, Recife, 2013. 
SOLLA, Jorge; CHIORO, Arthur. Atenção ambulatorial especializada. In: GIOVANELLA, Lígia et al. (org.). Políticas e Sistema de Saúde no Brasil. 2. ed. Rio de Janeiro: FIOCRUZ, 2012.

SOUSA, Aione Maria da Costa. Universalização da saúde no Brasil e as contradições da sua negação como direito de todos. Revista Katálysis, Florianópolis, v. 17, n. 2, p. 227-234, jul./dez. 2014.

SOUZA, Camila Brandão et al. Estudo do tempo entre diagnóstico e início do tratamento do câncer de mama em idosas de um hospital de referência em São Paulo, Brasil. Ciência e Saúde Coletiva, Rio de Janeiro, v. 20, n.12, p. 3805-3816, dez. 2015.

TRAVASSOS, Claudia; CASTRO, Mônica Silva Monteiro de. Determinantes e desigualdades sociais no acesso e na utilização de serviços de saúde. In: GIOVANELLA, Lígia et al. (org.). Políticas e Sistema de Saúde no Brasil. 2. ed. Rio de Janeiro: FIOCRUZ, 2012.

USTÁRROZ, Elisa. Omissão estatal e responsabilidade objetiva pela fuga de presos. In: FREITAS, Juarez; TEIXEIRA, Anderson Vichinkeski. Comentários à jurisprudência do STF: direitos fundamentais e omissão inconstitucional. Barueri: Manole, 2012. 


\section{ANEXO A}

Q208/2016

\section{Informações do Registro Hospitalar de Câncer - Tabulador Hospitalar Base do Estado: RS}

Número de casos por Ano de 1 consulta segundo Unidade hospitalar Período: 2010-2015

Localização primária detalhada: C50.0 Mamilo, C50.1 Porção central da mama, C50.2 Quadrante superior interno da mama, C50.3 Quadrante inferior interno da mama, C50.4 Quadrante superior externo da mama, C50.5 Quadrante inferior externo da mama, C50.6 Prolongamento axilar da mama, C50.8 Lesão sobreposta da mama, C50.9 Mama, SOE (exclui pele da mama C44.5)

\begin{tabular}{|c|c|c|c|c|c|c|}
\hline $\begin{array}{l}\text { Unidade hospitalar } \\
\text { TOTAL }\end{array}$ & \begin{tabular}{|l|l|}
2010 \\
3459
\end{tabular} & \begin{tabular}{l|l|}
2011 \\
3352 \\
\end{tabular} & $\begin{array}{|ll|}2012 & 2013 \\
2590 & 2833 \\
\end{array}$ & $\begin{array}{l}2014 \\
1280 \\
\end{array}$ & $\begin{array}{r}2015 \\
101 \\
\end{array}$ & $\begin{array}{l}\text { Total } \\
13615 \\
\end{array}$ \\
\hline 2223546 HOSPITAL POMPÉIA & 44 & 118 & $109 \quad 111$ & 88 & 0 & 470 \\
\hline 2232022 HOSPITAL DA FUNDAÇÃO HOSPITAL CENTENÁRIO & 258 & 285 & $245 \quad 266$ & 258 & 0 & 1312 \\
\hline 2232057 HOSPITAL REGINA DE NOVO HAMBURGO & 32 & 70 & 80 & 0 & 0 & 258 \\
\hline 2232995 A.C. SANTA CASA DO RIO GRANDE. HCODPB & 71 & 45 & $89 \quad 95$ & 0 & 0 & 300 \\
\hline $\begin{array}{l}2237253 \text { IRMANDADE SANTA CASA DE MIISERICÓRDIA - PORTO } \\
\text { ALEGRE }\end{array}$ & 653 & 758 & 0 & 0 & 이 & 1411 \\
\hline $\begin{array}{l}2237571 \text { HOSPIIAL NOSSA SENHORA DA CONCEIÇÃO PORTO } \\
\text { ALEGRE }\end{array}$ & 196 & 206 & & 0 & 0 & 402 \\
\hline 2237601 HOSPIIAL DE CLÍNICAS - PORTO ALEGRE & 131 & 119 & $\begin{array}{ll}156 & 148\end{array}$ & 153 & 0 & 707 \\
\hline 2241021 HOSPITAL BARTHOLOMEU TACCHINI & 106 & 113 & $216 \quad 319$ & 0 & 0 & 754 \\
\hline 2244306 HOSPITAL UNIVERSTTÁRIO DE SANTA MARIA & 165 & 172 & 184206 & 0 & 0 & 727 \\
\hline 2246929 HOSPITAL DA CIDADE DE PASSO FUNDO & 130 & 147 & 151156 & 197 & 0 & 781 \\
\hline 2246988 HOSPITAL SÃO VICENTE DE PAULO - RS & 274 & 191 & $258 \quad 312$ & 0 & 0 & 1035 \\
\hline 2248190 HOSPITAL GERAL SANTA CASA DE URUGUAIANA & 152 & 133 & 0 & 0 & 0 & 285 \\
\hline 2252287 HOSPITAL BRUNO BORN & 115 & 77 & $115 \quad 152$ & 140 & 0 & 599 \\
\hline 2252694 HOSPITAL ESCOLA DA UFPEL & 116 & 87 & $137 \quad 123$ & 0 & 0 & 463 \\
\hline 2253054 SANTA CASA DE MISERICÓRDIA DE PELOTAS & 160 & 175 & $128 \quad 234$ & 194 & 0 & 891 \\
\hline 2254611 HOSPITAL VIDA E SAÚDE & 73 & 72 & 54 & 94 & 0 & 363 \\
\hline 2255936 HOSPITAL ANA NERY & 125 & 97 & $\begin{array}{ll}116 & 147 \\
\end{array}$ & 0 & 0 & 485 \\
\hline 2261057 HOSPITAL DE CARIDADE DE LUÍ & 169 & 160 & 216230 & 0 & 0 & 775 \\
\hline 2261987 SANTA CASA DE CARIDADE DE BAGE & 34 & 78 & 71 & 0 & 0 & 183 \\
\hline 2262274 HOSPIIAL DE CARIDADE DE CARAZINHO & 31 & 21 & 27 & 0 & 0 & 100 \\
\hline 2262568 HOSPITAL SÃO LUCAS DA PUC & 34 & 19 & 22 & 46 & 101 & 233 \\
\hline 2263858 HOSPIIAL DE CARIDADE SAO VICENTE DE & 23 & 0 & 0 & 0 & 0 & 23 \\
\hline 2265052 HOSPITAL FÊMIINA & 197 & 65 & 70 & 0 & 0 & 332 \\
\hline 2266474 HOSPITAL DE CARIDADE DE CACHOEIRA DO SUL & 60 & 64 & 48 & 0 & 0 & 243 \\
\hline $\begin{array}{l}2707918 \text { FUNDAC̣ÃO HOSPITALAR SANTA TEREZINHA DE } \\
\text { ERECHIM }\end{array}$ & 110 & 80 & 98 & 110 & 이 & 483 \\
\hline
\end{tabular}

\section{Copiacome CSV}

Fonte: Sistema de Registro Hospitalar de Cancer(SisRHC)

* Os dados coletados pelos Registros Hospitalares de Cancer nåo devem ser utilizados para calculo de incidencia, uma vez que retratam apenas o perfil de atendimento de uma determinada instituiçăo (ou de um grupo destas.) 
Recebido em: 23-09-2017

Aprovado em: 27-06-2019

\section{Brunize Altamiranda Finger}

Mestre em Direito Público pelo Programa de Pós-Graduação em Direito da Unisinos. Professora Substituta na Faculdade de Direito da Universidade Federal do Rio Grande (FURG). Advogada.

E-mail: brunizefinger@gmail.com

\section{Têmis Limberger}

Pós-doutora em Direito pela Universidade de Sevilha Doutora em Direito Público pela Universidade Pompeu Fabra - UPF de Barcelona . Mestre em Direito pela Universidade Federal do Rio Grande do Sul (UFRGS). Professora da Universidade do Vale do Rio dos Sinos (Unisinos) nos cursos de graduação e pós-graduação. Procuradora de Justiça do Ministério Público do Estado do Rio Grande do Sul. Membro do Instituto Brasileiro de Direito Eletrônico - IBDE, da Federación Iberoamericana de Asociaciones de Derecho e Informática - FIADI e da Rede Brasileira de Pesquisadores em Direito Internacional.

E-mail: temis@via-rs.net

Universidade do Vale do Rio dos Sinos (UNISINOS). Programa de Pós-Graduação em Direito.

Av. Unisinos, 950 - Cristo Rei, São Leopoldo - RS, CEP: 93022-750. 
